\title{
Postgraduate medical students' acceptance and understanding of scientific information databases and electronic resources
}

\author{
Mohammad Azami ${ }^{1}$, Reza Khajouei ${ }^{2}$, Safiyeh Rakhshani ${ }^{3}$
}

${ }^{1}$ Ph.D., Assistant Professor, Modeling in Health Research Center, Institute for Futures Studies in Health, Kerman University of Medical Sciences, Kerman, Iran

${ }^{2}$ Ph.D., Associate Professor, Medical Informatics Research Center, Institute for Futures Studies in Health, Kerman University of Medical Sciences, Kerman, Iran

${ }^{3}$ M.Sc., Department of Medical library and information Sciences, Faculty of Management and Medical Information, Kerman University of Medical Sciences, Kerman, Iran

\section{Type of article: Original}

\begin{abstract}
Introduction: The significance and validity of web-based scientific databases are increasing dramatically in the scientific community. Moreover, a great number of students use these resources without having sufficient and accurate knowledge and understanding. In order for students to use these databases and electronic resources optimally, identifying the factors that affect the understanding and acceptance of these resources seems necessary. The aim of this study was to determine postgraduate medical students' acceptance and understanding of these resources.

Methods: This cross-sectional study was conducted on 311 postgraduate medical students from Kerman University of Medical Science (KMU) in 2013. Data were collected using a researcher-made questionnaire, and the data were analyzed using SPSS. In order to design the model (i.e., the interaction between study variables and to determine the relationships between them in an integrated pattern), LISREL version 8.7 and a structural equation model were used. Descriptive statistics and t-tests also were used in data analysis.

Results: The results showed that the average components of the perception of usefulness, perception of ease of use, attitude towards use, decision to use, using to perform duties, and using to increase knowledge were 4.31, $4.14,4.24,16.27,20.85$, and 16.13 respectively. Accordingly, the average of all these indicators was significantly higher than the assumed amount $(\mathrm{p}<0.01)$. Moreover, the results obtained from factor analysis and the structural equation model indicated that the model of the present study fit the data perfectly.

Conclusions: Based on the findings of this study, the more these databases are considered useful and easy to use, the more they are used. Therefore, designers of databases and electronic resources can design systems that are both useful and easy to learn by considering the components of the research model.

Keywords: scientific information databases, technology acceptance model, graduate students
\end{abstract}

\section{Introduction}

In recent decades, significant progress has been made in the application of information technologies and communication technologies in the search and recovery of information resources. One of the areas that has dramatically changed after the introduction of information technology is medical education. It aims to educate skilled people through obtaining the knowledge and skills necessary to cure patients with early diagnosis. Most medical schools have provided students with facilities in this field. The atmosphere that affects these environments has changed, i.e., teaching and learning methods have improved (1). One of these improvements includes students' access to information resources on the web. Medical information databases and electronic resources are some resources that provide students with valid and up-to-date scientific information (2).

\section{Corresponding author:}

Safiyeh Rakhshani, Department of Medical library and information Sciences, Faculty of Management and Medical Information, Kerman University of Medical Sciences, Kerman, Iran.

Tel: +98.9155493302, Fax: +98.3431325221, E-mail: safiyeh66@yahoo.com

Received: August 18, 2015, Accepted: January 24, 2016, Published: February 2016

iThenticate screening: November 16, 2015, English editing: January 28, 2016, Quality control: February 03, 2016

(C) 2016 The Authors. This is an open access article under the terms of the Creative Commons Attribution-NonCommercialNoDerivs License, which permits use and distribution in any medium, provided the original work is properly cited, the use is non-commercial and no modifications or adaptations are made. 
Due to the comprehensiveness and quality of the information in the databases, these resources are considered the most important and reliable sources of information for research and knowledge production among students $(3,4)$. Electronic resources have exploded in popularity, and they are being used extensively to increase the creation of new fields of research. Other reasons for medical students to use e-resources include relating to increasingly computer-literate colleagues and patients and keeping up to date in their fields. Furthermore, it is essential for those in clinical practice, since more of their clients use e-resources to keep informed about health information (5).

In order to optimize the application of information databases and electronic resources by students, evaluating the understanding level and factors that influence the acceptance and use of these resources is very important. Studies have shown that having access to more information databases and electronic resources and using them are not easy. For example, students faced difficulties in interacting with, operating, and using databases. Moreover, the user interface of these databases makes users' access to information more difficult and causes confusion (6-8). One of the ways that can help to fix this problem is the application of valid models and theories that are available to study students' acceptance patterns and their application of these databases. One of the theories that can be useful in evaluating users' acceptance and level of understanding of information databases and electronic resources is the Technology Acceptance Model. This theory examines the factors that affect students' acceptance and understanding of information technology, which are affected by internal and external factors. Internal factors include perception of ease of use, perception of usefulness, and people's attitudes towards deciding to use and actually using information technology. External factors include fulfilling duties, increasing knowledge, organizational factors, social factors, and characteristics of computer systems, and they also are addressed in this theory (9). All internal factors and some external factors (fulfilling duties and increasing knowledge) were examined in this study. All of these factors affect people's attitudes towards the use of technology and result in their making decisions to use information technologies. Technology Acceptance Model can be used to predict users' acceptance or rejection of a technology (10). According to the available resources, no research has been done in Iran on students' acceptance and understanding level of information databases and electronic resources based on this model. However, a few studies have tried to use this model in various fields, such as information technology (11), Internet services (12), mobile phones and computers (13), electronic learning (14), and electronic banking and Internet shopping (15). Most of the foreign studies done on the Technology Acceptance Model have evaluated information technologies (16), Internet and electronic resources (17-20), and digital libraries $(21,22)$. In general, these studies have tried to examine the factors that affect the acceptance of information technologies in various areas. Since graduate students constitute a wide range of active users of information databases and electronic resources, the aim of this research was to use the based on Technology Acceptance Model to evaluate and analyze the understanding and acceptance of information databases and electronic resources by the graduate students at Kerman University of Medical Science.

\section{Material and Methods}

This study was a cross-sectional, analytical study. Data were collected using a questionnaire designed based on the Technology Acceptance Model. Concerning the objectives of this study, the study population consisted of all post graduate students studying at Kerman University of Medical Sciences in the academic year 2012-2013. This questionnaire consisted of two parts. The first part was related to demographic information, and the second part was about concepts and categories of the Technology Acceptance Model. It had 30 questions in six categories. Questions 1 to 5 were about the perception of usefulness; questions 6 to 10 were related to the perception of ease of use; questions 11 to 16 were related to attitudes towards use; questions 17 to 21 were about making decisions to use; questions 22 to 26 were allocated to fulfilling duties; and questions 27 to 30 were related to increasing knowledge. The questions were answered by choosing one of the following options: strongly agree, agree, I'm not sure, disagree, and strongly disagree based on the Likert 5-option scale. The validity of this questionnaire was approved by five faculty members of the Department of Library and Medical Information and Medical Informatics. Its reliability also was confirmed by the test-retest method and Cronbach's alpha (0.91). The statistical population consisted of all graduate students at Kerman University of Medical Science in the academic year 2012-2013 $(n=320)$. The stratified random sampling method was used in this research. To do this, every college was considered a category, and the necessary sample was taken such that it was proportional to the number of students in that college. Data were collected by going to the colleges, distributing questionnaires among students, and collecting the questionnaires after the students had completed them. To analyze the data, descriptive statistics and t-tests were used. We used SPSS software to analyze the data. The significance level was 0.05 , and the hypothetical average was considered to be 3 in this study. This average was obtained from the average scores given to the options of the Likert scale (1-5). Moreover, LISREL software, version 8.7, and structural equation patterns were used to confirm the model, 
determine the effects of each variable, and determine the relationships between them in the form of an integrated pattern.

\section{Results}

\subsection{General findings}

Among the 320 questionnaires distributed among the students, 311 (97\%) were returned. Most respondents were female $(76 \%)$, and $61 \%$ of the respondents had a Master's degree. The percentage of respondents who used information databases and electronic resources at least once a day $(27 \%)$ was more than the percentage of other. The percentage of students who used these resources two to three times a month $(5 \%)$ was less than percentage of other students. Finally, we presented the factors that affected the participants' acceptance and level of understanding of the information databases and electronic resources based on the Technology Acceptance Model.

\subsection{Perception of usefulness}

To evaluate this variable, 5 criteria (questions) were used in the questionnaire. The mean of the respondents' perception of usefulness of information databases and electronic resources was slightly more than 4 in all 5 of the criteria based on the Likert 5-choice scale. The results of univariate t-test showed that the mean score of respondents to the perception of the usefulness of information databases and electronic resources was 4.31; it was significantly higher than the hypothetical average, i.e., $3(\mathrm{p}<0.01)$ (Table 1$)$.

Table 1. Perception of usefulness of information databases and electronic resources

\begin{tabular}{|l|l|l|l|l|}
\hline Index & $\mathrm{n}$ & Mean & $\begin{array}{l}\text { SD } \\
\text { Average } \\
\text { hypothesis }\end{array}$ \\
\hline $\begin{array}{l}\text { Perception of usefulness of information databases and electronic } \\
\text { resources }\end{array}$ & 311 & 31.4 & 53.0 & 3 \\
\hline $\begin{array}{l}\text { Perception of ease of use of information databases and electronic } \\
\text { resources }\end{array}$ & 311 & 14.4 & 560. & 3 \\
\hline Attitude towards use of information databases and electronic resources & 311 & 24.4 & 53.0 & 3 \\
\hline Decision to use information databases and electronic resources & 311 & 27.16 & 20.2 & 12 \\
\hline Using information databases and electronic resources to perform tasks & 311 & 85.20 & 20.2 & 15 \\
\hline $\begin{array}{l}\text { Using information databases and electronic resources to increase } \\
\text { knowledge }\end{array}$ & 311 & 83.16 & 79.1 & 12 \\
\hline
\end{tabular}

\subsection{Perception of ease of use}

To evaluate this variable, 5 criteria (questions) were used in the questionnaire. Of the 5 criteria examined above, the criteria "ease of acquiring a skill" and "ease of use" were higher $(m e a n=4)$ than the other criteria. The results of univariate t-test showed that the mean score of the respondents to the perception of ease of use of information databases and electronic resources was 4.14; this was significantly higher than the average score, i.e., 3 ( $p<0.01)$.

\subsection{Attitude towards usage}

To evaluate this variable, 6 criteria (questions) were used in the questionnaire. The results of examining the criteria related to attitudes towards using information databases and electronic resources showed that the mean score of Likert scale was more than 4 for all criteria, with "useful," "positive," and "good" criteria being about 4.25. The results of the univariate t-test showed that the mean score of the respondents to the attitude towards using information databases and electronic resources was 4.24; it was significantly higher than the average score, i.e., 3 ( $p$ $<0.01$ ) (Table 1).

\subsection{Making decisions to use}

The results of examining the average criteria of this aspect showed that the mean score of Likert scale was more than 4 for all of the criteria except "willingness to use if available" (mean = 3.86). The results of the univariate t-test showed that the mean score of the respondents concerning decisions to use information databases and electronic resources was 16.27, which was significantly higher than the average score, i.e., $12(\mathrm{p}<0.01)$ (Table 1). 


\subsection{Using to fulfill duties}

The results of examining the criteria related to the aspect "using information databases and electronic resources to fulfill duties" showed that the mean score of the Likert scale was more than 4 for all criteria, with "ease of fulfilling duties" being the highest $($ mean $=4.30)$. The results of the univariate t-test showed that the mean score of the respondents concerning "using information databases and electronic resources to fulfill duties" was 20.85, which was significantly higher than the hypothetical average, i.e., $15(\mathrm{p}<0.01)($ Table 1$)$.

\subsection{Evaluating usage level to increase knowledge}

The results of examining the criteria related to the aspect "using information databases and electronic resources to increase knowledge" showed that the mean score of the Likert scale was more than 4.2 for all of the criteria. According to the results of the univariate t-test, the mean score of the respondents concerning "using information databases and electronic resources to increase knowledge" was 16.83 , which was significantly higher than the hypothetical average, i.e., $12(\mathrm{p}<0.01)$ (Table 1). The results of examining all 6 concepts and categories of Technology Acceptance Model are presented in Table 1. As shown in Table 1, the results of the univariate t-test suggested that the average respondents' score to the perception of the usefulness of information databases and electronic resources, the perception of the ease of use of information databases and electronic resources, and the attitude towards the use of information databases and electronic resources were 4.31, 4.14, and 4.24, respectively; all of them were higher than the average hypothesis i.e., 3. Using the t-test, these differences were 43.24, 35.51, and 36.41 , respectively; the degree of freedom (310) was significant at $99 \%(\mathrm{p}<0.01)$. Concerning the decision to use information databases and electronic resources, the respondents' average score was 16.27. Making use of information databases and electronic resources to increase knowledge was 16.83 , which was higher than the average hypothesis, i.e., 12; these differences were 34.23 and 47.56, respectively, and they were significant with the degree of freedom of 310 at $99 \%(\mathrm{p}<0.01)$. Moreover, the average score of the respondents to the use of information databases and electronic resources to perform tasks was 20.85 , which was higher than the average hypothesis, i.e., 15; using the t-test, this difference was 46.86 and the degree of freedom $(310)$ was significant at $99 \%(\mathrm{p}<0.01)$. Therefore, it could be concluded statistically that the respondents had a positive perception of the usefulness and the ease of use of information databases and electronic resources, and they had a positive attitude to wards information databases and electronic resources. They also believed that information databases and electronic resources enhanced their knowledge.

\subsection{Model fitness test}

The structural equation modeling method and LISREL software were used to test the model's fitness and to study the relationships between its variables. Concerning the index "goodness of model totality," the relationship between users' acceptance and understanding level of the information databases and electronic resources and model components were strong. The results showed that the users' acceptance and understanding level of information databases were approved and fitted based on the Technology Acceptance Model. Figure 1 shows the model's standard coefficients indicating the relationships between the variables.

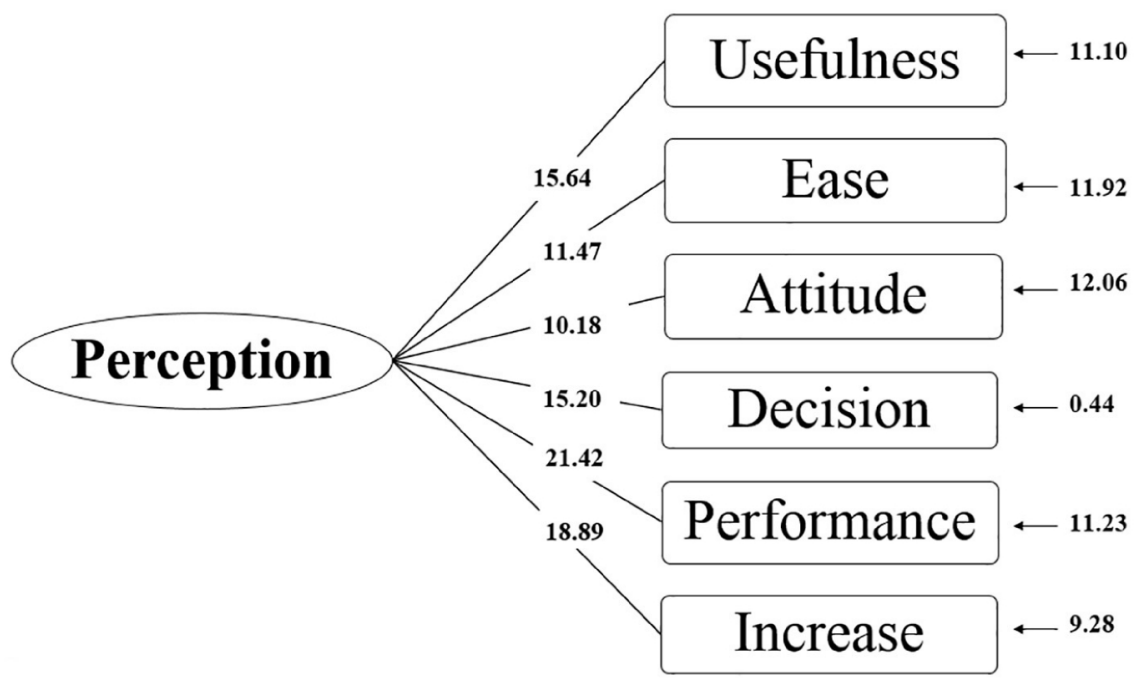

Figure 1. Standard coefficients evaluated in LISREL Software 
The coefficients of the t-values in the structural equations represented confirmation or rejection of the hypotheses; if the coefficient were greater than 2, the hypothesis was confirmed, otherwise it was rejected. In this study, all coefficients of the t-values were greater than 2, indicating confirmation of the model's variables. Statistically, it could be concluded that the entire model was approved and had a suitable and significant fit. Figure 2 shows the coefficients of the t-values.

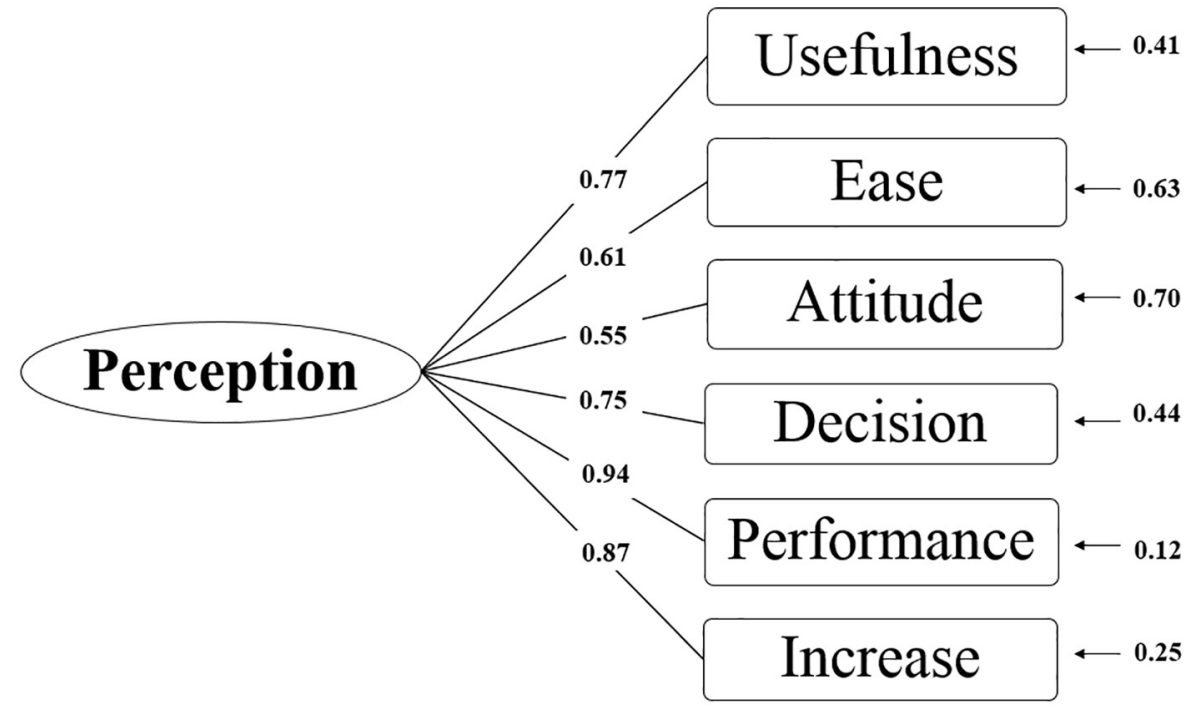

Figure 2. t-value amounts in LISREL Software

\section{Discussion}

The results of this research indicated that the graduate students' understanding and perception of information databases and electronic resources were desirable based on the Technology Acceptance Model. Moreover, there was a significant positive relationship between the users' acceptance and understanding of the information databases, electronic resources, and the model's components. The results of the present study were in line with the results of previous studies; a study by Nazemi and Mirabi showed that there was a positive significant relationship between ease of use and perception of usefulness of the technology (12). The results of this study were also confirmed concerning the positive perception of technology. Zamani et al. showed that there was a relationship between the perception of ease of use, perception of usefulness, attitudes towards using, and making decisions to use IT (13). Moreover, the results of a study conducted by Salari et al. showed that there was a correlation between the two factors of "perception of ease of use and perception of usefulness" and acceptance of electronic learning (14). The results of a study by Bagheri et al. showed significant effects of perception of usefulness, perception of ease of use, and trust in attitudes towards using technology (15). The results of this research also were in line with the results of studies conducted by Thong et al. They showed that both perception of usefulness and perception of ease of use were factors that determined acceptance of digital libraries by users (22). The results indicated that, as users' performance improved in information databases and electronic resources, these resources would seem more useful to them; as a result, it increased their acceptance and understanding of information databases and electronic resources. Moreover, as improvements occurred in the users' positive attitude, decisions to use information databases and electronic resources, fulfilling duties by using information databases and electronic resources, and increasing knowledge by using information databases and electronic resources, their acceptance and understanding level increased. Makizade et al. mentioned that "intentions to do an action or making decisions to use" were the factors that affected a person's decision to use information databases available at a university to do scientific activities (23). The results of a study by Dorani and Rashidi showed that there was a significant relationship between the variables "perception of ease of use and perception of usefulness" and "attitudes towards Information technology". Moreover, perception of usefulness affected decisions to use IT and provided opportunity to use IT (24). Other findings indicated that there was a significant relationship between perceived usefulness and decision to use technologies $(25$, 26).

The results of the structural equation model showed that the totality of the model was confirmed based on the Technology Acceptance Model and on users' acceptance and understanding level of the information databases and 
electronic resources. A study conducted by Ahmadi Deh Ghotbadini indicated that the IT adoption model had good fitness with the data (27). Seyed Javadadin and Yazdani showed in their study that the technology Acceptance Model was an appropriate model to explain the behavior of using Internet banking services. In addition, this model was useful in understanding the intended use of IT services. There was a significant relationship between ease of perceived use and individual's perception of usefulness of using these services and the intention to use technology (28).

\section{Conclusions}

The results of this study showed that the students had a good understanding of the information databases and electronic resources and that they accepted those resources. The students' acceptance and understanding of scientific information databases and electronic resources resulted in their decisions to use those resources in doing their homework and to conduct research. Therefore, the results of this study can be used to design and implement some capabilities proportional to users' needs concerning the information databases and electronic resources in order to increase the quality of medical education and medical research. It also is recommended that educational authorities develop information resources that are more consistent with the needs of education and research students. Due to the importance of electronic information resources for the medical community, careful planning is required of the health policy makers and managers of library and information centers of the Kerman Medical University in order to introduce the facilities and capabilities of the resources, especially the electronic resources. In addition to examining students' satisfaction with these resources, future research should investigate the correlation between students' satisfaction and their impact on training effectiveness.

\section{Acknowledgments:}

We would like to show our gratitude to the staff members in the Department of Medical Library and Information Sciences at Kerman Medical University for their help and support during the course of this research, and we thank the reviewers for their comments, which greatly improved the manuscript.

\section{Conflict of Interest:}

There is no conflict of interest to be declared.

\section{Authors' contributions:}

All authors contributed to this project and article equally. All authors read and approved the final manuscript.

\section{References}

1) Cheung Kong S. A curriculum framework for implementing information technology in school education to foster information literacy. Comput Educ. 2008; 51: 129-41. doi: 10.1016/j.compedu.2007.04.005.

2) Papi A, Ghazavi R, Moradi S. Determining the level of awareness of the physicians in using the variety of electronic information resources and the effecting factors. J Educ Health Promot. 2015; 4: 49. doi: 10.4103/2277-9531.162316, PMID: 26430676, PMCID: PMC4579771.

3) Teo T. Modeling technology acceptance in education: A study of pre-service teachers. Comput Educ. 2009; 52: 302-12. doi: 10.1016/j.compedu.2008.08.006.

4) Hira T, Zia W. Use of electronic information resources by the students of the faculty of science, University of Karachi. Int J Digit Account Res. 2014; 4(3): 80-91 .

5) Roach A, Addington W. The effects of information sources on medical education. Journal of Medical Education. 2001; 49: 176-280.

6) Atakan C, Atilgan D, Bayram O, Arslantekin S. An Evaluation of the second survey on electronic databases usage at Ankara University digital library. Electron Libr. 2008; 26; (2): 249-59. doi: 10.1108/02640470810864136.

7) Lederer AL, Maupin DJ, Sena MP, Zhuang Y. The technology acceptance model and the World Wide Web. Decis Support Syst. 2005; 29: 269-82. doi: 10.1016/S0167-9236(00)00076-2.

8) Aazami M, Fattahi R, Parirokh M. Evaluating graduate student's information seeking behavior in Ferdowsi University of Mashhad in database user interfaces based on Ellis's information seeking behavior. Library and Information Sciences. 2010; 60(15): 231-45. [In Persian].

9) Davis F, Fishbein M. Perceived usefulness, perceived ease of use and user acceptance of information technology: a comparison of two theoretical models. Management science. 1989; 35(8): 982-1003. doi: 10.1287/mnsc.35.8.982. 
10) Wixom BH, Todd PA. A theoretical integration of user satisfaction and technology acceptance. Inform Syst Res. 2005; 16: 85-102. doi: 10.1287/isre.1050.0042.

11) Sheikh shoaee F, Oloomi T. Factors Affecting Adoption of Information Technology by Colleges of Engineering. University of Tehran's public librarians. 2007; LIS (3): 9-34. [In Persian].

12) Nazmi Sh, Mirabi A. Introduction and test the acceptance conceptual model of Internet services and information technology among students of Ferdowsi University of Mashhad. Journal of Information Processing and Management. 2002; 28(1): 181-202. [In Persian].

13) Zemani B, Babri H, Mousavi S. Factors related to attitudes of medical students to embrace learning through mobile phones using the technology acceptance model. Journal of Medical Education Development Center. 2001; 9(2): 110-17. [In Persian].

14) Salari M. et al. Factors associated with the adoption of e-learning by nursing students. Journal of Education Sterategies in Medical Sciences. 2009; 2(3): 103-8. [In Persian].

15) Bagheri AM, Hamidi Beheshti MT, Alidoosti C. Adoption of internet banking in Iran: the development of technology acceptance model. Journal of Information Science and Technology. 2008; 3(57): 5-34.

16) Rose G, Straub D. Predicating General IT use: Applying TAM to the Arabic world. J Global Inform Manag .1998; 6(3): 39-46. doi: 10.4018/jgim.1998070104.

17) Tao D. Intention to use and actual use of electronic information resources: further exploring technology acceptance model (TAM). AMIA Annu Symp Proc. 2009; 2009: 629-33. PMID: 20351931, PMCID: PMC2815463.

18) Kripanont N. Using a technology acceptance model to investigate academic acceptance of internet. Journal of Business System, Governance and Ethics. 2006; 1(2): 13-28. doi: 10.15209/jbsge.v1i2.72.

19) $\mathrm{Lu} \mathrm{J}$, Yu C, liu C, Yao JE. Technology acceptance model for wireless internet. Internet Res. 2003; 13(3): 206- 22. doi: 10.1108/10662240310478222.

20) Spacey R, Goulding A, Murray I. The Power of influence: what affects public library staff's attitudes to the Internet? Library Management. 2004; 25(6): 270-6. doi: 10.1108/01435120410547922.

21) Kim YM. The Adoption of university library web Site resources: A multi group analysis. Journal of the American Society for Information Science and Technology. 2010; 61(5): 978-93. doi: 10.1002/asi.21308.

22) Thong JYL, Hong W, Tam K. Understanding user acceptance of digital libraries: what are the roles of interface characteristics, organizational context, and individual differences? Int J Hum Comput Stud. 2002; 57(3): 215-42. doi: 10.1016/S1071-5819(02)91024-4.

23) Makizadeh F. Identify factors affecting the adoption of web-based databases by academic users: a grounded theory study. Journal of Library and Information Studies. 2011; (59): 59-81. [In Persian].

24) Dorani K, Rashidi Z. Factors affecting the adoption of information technology by school teachers in Tehran, with emphasis on information technology acceptance model. Journal of Research in Educational Systems. 2007; 1(1): 46-62. [In Persian].

25) Chen $\mathrm{Yu}$ - Hui. Undergraduates' perceptions and use of the university libraries Web portal: Can information literacy instruction make a difference? Proceedings of the American Society for Information Science and Technology. 2011; 48(1): 1-10. doi: 10.1002/meet.2011.14504801051.

26) Farmani M, Kimiaee A, Fatollahzadeh F. Investigation of Relationship between ease of use, innovation tendency, perceived usefulness and intention to use technology: An empirical study. Indian Journal of Science and Technology. 2012; 5(11): 3678-82.

27) Ahmadi Deh Qutbal-Din, M. Relationship between the experience of working with computers, computer self-efficacy, perceived computer and technology acceptance model structures. Islamic Azad University project. 2007. [In Persian].

28) Javadein SR, Yazdani Sh. Factors affecting customer's intention to use internet banking services. Journal of Knowledge Management. 2005; 18(3): 31-49. [In Persian]. 